\title{
BMJ Open \\ HIV virological failure and drug resistance among injecting drug users receiving first-line ART in China
}

\author{
Xuebing Leng, ${ }^{1}$ Shujia Liang, ${ }^{2}$ Yanling Ma, ${ }^{3}$ Yonghui Dong, ${ }^{4}$ Wei Kan, ${ }^{1}$ \\ Daniel Goan, ${ }^{5}$ Jenny H Hsi, ${ }^{1}$ Lingjie Liao, ${ }^{1}$ Jing Wang, ${ }^{1}$ Cui He, ${ }^{1}$ Heng Zhang, ${ }^{1}$ \\ Hui Xing, ${ }^{1}$ Yuhua Ruan, ${ }^{1}$ Yiming Shao ${ }^{1}$
}

To cite: Leng $X$, Liang $S$, Ma Y, et al. HIV virological failure and drug resistance among injecting drug users receiving first-line $A R T$ in China. BMJ Open 2014;4: e005886. doi:10.1136/ bmjopen-2014-005886

- Prepublication history for this paper is available online. To view these files please visit the journal online (http://dx.doi.org/10.1136/ bmjopen-2014-005886).

$\mathrm{XL}, \mathrm{SL}, \mathrm{YM}, \mathrm{YD}$ and WK contributed equally to this work.

Received 10 June 2014 Revised 29 July 2014 Accepted 18 August 2014

CrossMark

For numbered affiliations see end of article.

Correspondence to

Hui Xing;

xingh@chinaaids.cn

\section{ABSTRACT}

Objective: To explore HIV virological failure and drug resistance among injecting drug users (IDUs) receiving first-line antiretroviral treatment (ART) in China.

Design: A series of cross-sectional surveys from 2003 to 2012 from the Chinese National HIV Drug Resistance (HIVDR) Surveillance and Monitoring Network.

\section{Setting: China.}

Participants: Data were analysed by the Chinese National (HIVDR) Surveillance and Monitoring Network from 2003 to 2012. Demographic, ART and laboratory data (CD4+ cell count, viral load and drug resistance) were included. Factors associated with virological failure were identified by logistic regression analysis.

Results: 929 of the 8556 individuals in the Chinese HIVDR database were IDUs receiving first-line ART. For these 929 IDUs, the median duration of treatment was 14 months (IQR 6.0-17.8). 193 of the 929 IDUs $(20.8 \%)$ experienced virological failure (HIV viral load $\geq 1000$ copies $/ \mathrm{mL}$ ). The prevalence of HIVDR among patients with virological failure was $38.9 \%$ (68/175). The proportion of patients with drug resistance to nonnucleoside reverse transcriptase inhibitor (NNRTIs), nucleoside reverse transcriptase inhibitor (NRTIs) and protease inhibitors (PIs) was $52.9 \%, 76.5 \%$ and $4.4 \%$, respectively. Factors independently associated with virological failure include: ethnic minorities, junior high school education or less, farmers, self-reported missing doses in the past month, CD4 cell count at survey from 200 to 349 cells $/ \mathrm{mm}^{3}$ or from 0 to 199 cells/ $/ \mathrm{mm}^{3}$, and residence of Guangxi and Yunnan provinces.

Conclusions: The proportion of virological failure was high among IDUs receiving first-line ART in China. However, better treatment outcomes were observed in Guangxi and Yunnan, which indicates the importance of ART education and adherence to intervention, especially for patients who are farmers, minorities or have a poor educational background.

\section{INTRODUCTION}

Since the early 1990s, highly active antiretroviral therapy (HAART) has been used to treat

\section{Strengths and limitations of this study}

- This study is a large sample from the Chinese National HIV Drug Resistance (HIVDR) Surveillance and Monitoring Database that was obtained from a series of cross-sectional surveys from 2003 to 2012.

- The prevalence of injecting drug users (IDUs) in southwest China is serious; however, IDUs in Guangxi and Yunnan showed promising results from antiretroviral treatment and had fewer virological failures.

- The outcomes of this study may not fully represent all IDUs in China.

- Owing to the long time span covered by the data in our study, changes to prevention policies and treatment programmes may have influenced the effectiveness of the treatment.

- Our study can only provide a reference for the diverse localities studied, with each having different epidemic and intervention situations.

HIV-infected patients worldwide, improving immune reconstitution and decreasing AIDS-related mortality. ${ }^{1-3}$ Unfortunately, incomplete viral suppression may lead to the development of HIV drug resistance, which not only compromises therapeutic effects for an individual, but also endangers the population as a whole. ${ }^{4}$

In 2012, UNAIDS reported that injecting drug users (IDUs) worldwide were the population most at risk to be affected by HIV. Based on data from 49 countries, the rate of HIV infection of IDUs was 22 times that of the general population. ${ }^{5}$ In China, where sex has becoming the main route of HIV transmission, HIV prevalence in IDUs is higher for female sex workers and men who have sex with men. ${ }^{6}{ }^{7}$ In 2003, the 'four free one care' policy was introduced, which provided free antiretroviral treatment for all eligible HIV patients in China. According to the analysis of the $2013 \mathrm{HIV} / \mathrm{STD}$ epidemic in 
China, more than 278000 patients had received the free antiretroviral treatment. ${ }^{8}$ Since 2004, methadone maintenance treatment (MMT), needle exchange and harm reduction have gradually expanded in China; this has improved the adherence of IDUs to treatment and reduced HIV transmission. However, a previous smaller study showed that when compared to other patients, the proportion of virological failure among IDUs was higher. ${ }^{9}$ Taking into consideration the conditions of IDUs in China, a large sample from the Chinese National HIV Drug Resistance (HIVDR) Surveillance and Monitoring Database was used to analyse and determine the prevalence of virological failure and drug resistance among IDUs receiving the first-line ART in China.

\section{METHODS}

Study design and study participants

We collected data through the Chinese National HIVDR Surveillance and Monitoring Network, which consists of four core laboratories (National Center for AIDS/STD Control and Prevention (NCAIDS), Shanghai Municipal Center for Disease Control and Prevention (CDC), Chinese Medical University Center for AIDS Research, and Institute of Microbiology and Epidemiology of the Chinese Academy of Military Medical Sciences) and laboratories from 30 provincial CDCs. ${ }^{10}$ IDUs were defined as patients who had a history of self-reported drug injection. Samples were obtained from a series of cross-sectional surveys from 2003 to 2012 on HIV drug resistance in adult patients at nationally representative ART clinics. The inclusion criteria were: (1) HIV infected IDU; (2) age $\geq 18$ years; (3) onset of HAART between 1 January 2003 and 31 December 2011; (4) received free national first-line ART treatment; (5) consent and willingness to participate in the study.

\section{Data collection}

Data were collected through an interviewer-administered questionnaire. All participants provided written informed consent before participation in the study. Each participant was assigned a confidential identification number used to identify questionnaires and blood specimens. The questionnaire was administered face to face by a trained interviewer in a private room. Questionnaire questions included sociodemographic characteristics, HIV risk factors, HAART regimens and self-reported adherence measures. Demographic variables included sex, ethnicity, education level, occupation, marital status and HIV transmission route. Self-reported adherence variables included missed ART doses in the past month.

\section{Laboratory analysis}

Blood specimens were collected from all participants to test CD4 cell count, HIV viral load (VL) and HIV drug resistance mutations at the baseline survey. CD4 cell counts were determined by flow cytometry in the provincial CDC offices within $24 \mathrm{~h}$ of collection. Plasma HIV RNA was quantified with real-time NASBA (NucliSense Easy Q bioMerieux, France) or COBAS (Roche Applied Biosystems, Germany) according to the manufacturer's recommendations. Samples with VL $\geq 1000$ copies $/ \mathrm{mL}$ were selected for HIV drug resistance testing by using an in-house PCR. ${ }^{9}{ }^{10}$ In order to perform HIV drug resistance mutations, HIV-1 pol gene (protease 1-99 amino acids and part of the reverse transcriptase 1-252 amino acids) were amplified and analysed using the Stanford HIV Drug Resistance Database (http://hivdb.stanford.edu/). We included mutation results that conferred low-level, intermediate-level and high-level resistance. ${ }^{11} 12$

\section{Data analysis}

All questionnaire data were double-entered using Epidata 3.1 (The Epidata Association Odense, Denmark). Statistical Analysis System (SAS V.9.2, SAS Institute Inc, Cary, North Carolina, USA) was then used for data cleaning and analysis. Univariate logistic regression models were constructed to explore associations between virological failure, demographic characteristics, HAART regimens, adherence and CD4 data. OR and 95\% CIs were calculated as well. Variables that were significant $(p<0.05)$ in the univariate models were used in stepwise multivariate logistic regression models and presented with AOR and 95\% CIs. Owing to the large sample and according to some previous studies, ${ }^{9} 101314 \mathrm{p}<0.05$ was defined as statistically significant, and all tests were two sided.

\section{RESULTS}

\section{Demographic characteristics}

Of the 8556 patients in the National HIVDR Database who began treatment between 1 January 2003 and 31 December 2011, 929 IDUs matched the inclusion criteria. The demographic characteristics of the participants were shown in table 1 . In total, $90.8 \%$ were men; the mean age was $35.7 \pm 6$ years; $55.1 \%$ were ethnically Han; $60.8 \%$ had an education level of junior high school or higher; $23.4 \%$ were farmers; and more than half $(65.2 \%)$ were married.

\section{HAART regimens and virological profiles}

Initial HAART regimens were AZT+3TC+EFV (9.5\%), AZT $+3 \mathrm{TC}+\mathrm{NVP} \quad(34.8 \%), \mathrm{D} 4 \mathrm{~T}+3 \mathrm{TC}+\mathrm{EFV}(9.3 \%), \mathrm{D} 4 \mathrm{~T}+3 \mathrm{TC}$ + NVP $(32.8 \%)$, and DDI-based regimens (didanosine (DDI)+nevirapine (NVP) or efavirenz (EFV)) $(13.6 \%)$. HAART regimens at survey were AZT $+3 \mathrm{TC}+\mathrm{NVP} / \mathrm{EFV}$ (52.3\%), D4T+3TC+NVP/EFV (34.8\%), DDI-based regimens $(9.7 \%)$ and second-line regimens $(3.2 \%)$. At the time of the survey, $193(20.8 \%)$ patients had a VL $\geq 1000$ copies $/ \mathrm{mL}$. Among these participants, 175 were successfully genotyped. CRF07_BC was the most common HIV viral subtype $(41.7 \%)$, followed by CRF01_AE (27.4\%). Of these, 68 had detectable HIVDR mutations. 
Table 1 Characteristics of IDU patients receiving antiretroviral treatment in China

\begin{tabular}{|c|c|c|}
\hline Characteristics & Number & Percentage \\
\hline Total & 929 & \\
\hline Age (years): mean $\pm S D$ & $35.7 \pm 6.0$ & \\
\hline \multicolumn{3}{|l|}{ Sex } \\
\hline Male & 844 & 90.8 \\
\hline Female & 85 & 9.2 \\
\hline \multicolumn{3}{|l|}{ Ethnicity } \\
\hline Han & 512 & 55.1 \\
\hline Minorities & 417 & 44.9 \\
\hline \multicolumn{3}{|l|}{ Education } \\
\hline Illiterate & 101 & 10.9 \\
\hline Primary school & 263 & 28.3 \\
\hline Junior high school & 410 & 44.1 \\
\hline High school or more & 155 & 16.7 \\
\hline \multicolumn{3}{|l|}{ Occupation } \\
\hline Farmer & 217 & 23.4 \\
\hline Others & 712 & 76.6 \\
\hline \multicolumn{3}{|l|}{ Married } \\
\hline Yes & 606 & 65.2 \\
\hline No & 323 & 34.8 \\
\hline \multicolumn{3}{|l|}{ Initial ART regimen } \\
\hline AZT+3TC+EFV & 88 & 9.5 \\
\hline $\mathrm{AZT}+3 \mathrm{TC}+\mathrm{NVP}$ & 323 & 34.8 \\
\hline D4T+3TC+EFV & 86 & 9.3 \\
\hline D4T+3TC+NVP & 305 & 32.8 \\
\hline DDI-based regimens & 127 & 13.6 \\
\hline \multicolumn{3}{|l|}{ ART regimen at survey } \\
\hline AZT+3TC+NVP/EFV & 486 & 52.3 \\
\hline D4T+3TC+NVP/EFV & 323 & 34.8 \\
\hline DDI-based regimen & 90 & 9.7 \\
\hline Second-line regimens & 30 & 3.2 \\
\hline $\begin{array}{l}\text { Duration of ART (months): } \\
\text { median, IQR }\end{array}$ & $\begin{array}{l}14.0 \\
6.0-17.8\end{array}$ & \\
\hline \multicolumn{3}{|l|}{ Province } \\
\hline Xinjiang & 306 & 32.9 \\
\hline Yunnan & 184 & 19.8 \\
\hline Hunan & 174 & 18.7 \\
\hline Guangxi & 122 & 13.1 \\
\hline Sichuan & 42 & 4.5 \\
\hline Guizhou & 25 & 2.7 \\
\hline Guangdong & 19 & 2.1 \\
\hline Shandong & 12 & 1.3 \\
\hline Gansu & 12 & 1.3 \\
\hline Jiangxi & 10 & 1.1 \\
\hline Others & 23 & 2.5 \\
\hline
\end{tabular}

\section{HIV drug resistance mutations}

Among the participants with HIVDR mutations, 36/68 $(52.9 \%)$ patients were resistant to non-nucleoside reverse transcriptase inhibitor (NNRTIs) drugs. Fifty two of sixty eight $(76.5 \%)$ patients had drug resistance to nucleoside reverse transcriptase inhibitor (NRTIs) drugs. Three of sixty eight $(4.4 \%)$ patients were identified to have drug resistance to protease inhibitors (PIs). In addition, 21/68 (30.9\%) patients had multidrug resistance to NNRTIs and NRTIs. The most frequent
NNRTIs mutations occurred at position 103 in the RT (reverse transcriptase) region and NRTIs mutations occurred at position 184 in the RT region. PI mutations were also found at positions 47 and 46 in the PR (protease) region (table 2).

\section{Predictors for HIV virological failure}

The factors associated with HIV virological failure were examined in univariate logistic regression models; those found to be statistically significant were included in the multivariate logistic regression model. There were six

Table 2 HIV drug resistance mutations among IDU patients with drug resistance

\begin{tabular}{|c|c|c|}
\hline Antiretroviral drug & $\mathbf{N}(\%)$ & $\begin{array}{l}\text { HIV drug } \\
\text { resistance } \\
\text { mutations, N (\%) }\end{array}$ \\
\hline Total & $68(100.0)$ & \\
\hline $\begin{array}{l}\text { Non-nucleoside reverse } \\
\text { transcriptase inhibitors } \\
\text { (NNRTI }\end{array}$ & $36(52.9)$ & $\begin{array}{l}\mathrm{K} 103 \mathrm{~N} / \mathrm{R}, 18 \\
(26.5) \\
\mathrm{Y} 181 \mathrm{C}, 8(118)\end{array}$ \\
\hline Efavirenz (EFV) ${ }^{\star}$ & $36(52.9)$ & $\mathrm{K} 101 \mathrm{E} / \mathrm{P} / \mathrm{Q}, 5$ \\
\hline Nevirapine (NVP)* & $36(52.9)$ & $(7.4)$ \\
\hline Delavirdine (DLV) & $34(50.0)$ & G190A/Q/S, 4 \\
\hline Etravirine (ETV) & 8 (11.8) & $(5.9)$ \\
\hline \multirow[t]{7}{*}{ Rilpivirine (RPV) } & $2(2.9)$ & $\mathrm{V} 106 \mathrm{~A} / \mathrm{M}, 3$ (4.4) \\
\hline & & $\mathrm{E} 138 \mathrm{~A} / \mathrm{Q}, 2$ (2.9) \\
\hline & & A98G, $1(1.5)$ \\
\hline & & M230L, 1 (1.5) \\
\hline & & $\mathrm{P} 225 \mathrm{H}, 1$ (1.5) \\
\hline & & V179D, 1 (1.5) \\
\hline & & Y188H, 1 (1.5) \\
\hline Nucleoside reverse & 52 (76.5) & M184I/V, 38(55.9) \\
\hline transcriptase inhibitors & & $\mathrm{D} 67 \mathrm{G} / \mathrm{N}, 6$ (8.8) \\
\hline (NRTI, any) & & V75I/L/T, 4 (5.9) \\
\hline Emtricitabine (FTC) & $50(73.5)$ & $\mathrm{K} 65 \mathrm{R}, 3$ (4.4) \\
\hline Lamivudine $(3 \mathrm{TC})^{*}$ & $50(73.5)$ & Y115F, 2 (2.9) \\
\hline Abacavir (ABC) & $19(27.9)$ & K70E, 1 (1.5) \\
\hline Didanosine (DDI)* & $17(25.0)$ & L74V, 1 (1.5) \\
\hline Stavudine (D4T) $)^{\star}$ & $12(17.6)$ & M41L, 1 (1.5) \\
\hline Tenofovir (TDF)* & 9 (13.2) & $\mathrm{N} 41 \mathrm{~L}, 1$ (1.5) \\
\hline Azidothymidine $(\mathrm{AZT})^{\star}$ & 7 (10.3) & T69IN, 1 (1.5) \\
\hline
\end{tabular}

Protease inhibitors

(PI, any)

Tipranavir (TPV) $3(4.4)$

Fosamprenavir (FPV) $2(2.9)$

Lopinavir (LPV) ${ }^{*} \quad 2(2.9)$

I47V, 1 (33.3)

Nelfinavir (NFV)

$2(2.9)$

M46I, 1 (33.3)

Atazanavir (ATV)

$1(1.5)$

Darunavir (DRV)

$1(1.5)$

Indinavir (IDV)

$1(1.5)$

Saquinavir (SQV)

$1(1.5)$

Multi-drug resistance to 21 (30.9)

NNRTI and NRTI

${ }^{*}$ Provided through the National Free Antiretroviral Treatment Program (NFATP). 
factors that remained in the final multivariate models (table 3). Factors positively associated with virological failure include: Ethnicity (compared to Han ethnicity: minorities AOR 1.8, 95\% CI 1.3 to 2.6), education (compared to high school or greater: junior high school or less AOR 1.6, 95\% CI 1.0 to 2.7), occupation (compared to other jobs: farmer AOR 1.6, 95\% CI 1.1 to 2.3), selfreported missing doses in the past month (compared to not missing doses in the past month: AOR 1.6, 95\% CI 1.0 to 2.5 ), $\mathrm{CD} 4 \pm$ cell count at survey (compared to $\mathrm{CD} 4$

Table 3 Factors associated with HIV viral suppression failure (viral load $\geq 1000$ copies $/ \mathrm{mL}$ ) among IDU patients receiving antiretroviral treatment in China

\begin{tabular}{|c|c|c|c|c|c|c|}
\hline Variable & Number & $\begin{array}{l}\text { Viral suppression } \\
\text { Failure } \mathbf{N}(\%)\end{array}$ & $\begin{array}{l}\text { Crude } \\
\text { OR }(95 \% \mathrm{Cl})\end{array}$ & p Value & $\begin{array}{l}\text { Adjusted } \\
\text { OR }(95 \% \mathrm{Cl})\end{array}$ & p Value \\
\hline Total & 929 & $193(20.8)$ & & & & \\
\hline \multicolumn{7}{|l|}{ Age (years) } \\
\hline$<35$ & 436 & $95(21.8)$ & & & & \\
\hline$\geq 35$ & 493 & 98 (19.9) & 0.9 (0.6 to 1.2$)$ & 0.47 & & \\
\hline \multicolumn{7}{|l|}{ Sex } \\
\hline Male & 844 & $174(20.6)$ & & & & \\
\hline Female & 85 & $19(22.4)$ & $1.1(0.6$ to 1.9$)$ & 0.71 & & \\
\hline \multicolumn{7}{|l|}{ Ethnicity } \\
\hline Han & 512 & 85 (16.6) & & & & \\
\hline Minorities & 417 & $108(25.9)$ & 1.8 (1.3 to 2.4$)$ & $<0.01$ & 1.8 (1.3 to 2.6$)$ & $<0.01$ \\
\hline \multicolumn{7}{|l|}{ Education } \\
\hline High school or more & 155 & $23(14.8)$ & & & & \\
\hline Junior high school or less & 774 & $170(22.0)$ & 1.6 (1.0 to 2.6$)$ & 0.04 & 1.6 (1.0 to 2.7$)$ & 0.04 \\
\hline \multicolumn{7}{|l|}{ Occupation } \\
\hline Others & 712 & $133(18.7)$ & & & & \\
\hline Farmer & 217 & $60(27.6)$ & 1.7 (1.2 to 2.4$)$ & $<0.01$ & $1.6(1.1$ to 2.3$)$ & 0.02 \\
\hline \multicolumn{7}{|l|}{ Married } \\
\hline No & 323 & $70(21.7)$ & & & & \\
\hline Yes & 606 & $123(20.3)$ & $0.9(0.7$ to 1.3$)$ & 0.62 & & \\
\hline \multicolumn{7}{|l|}{ CD4 cell counts before ART } \\
\hline $0-199$ & 642 & 123 (19.2) & & & & \\
\hline 200-349 & 266 & $63(23.7)$ & $1.3(0.9$ to 1.8$)$ & 0.12 & & \\
\hline$\geq 350$ & 21 & 7 (33.3) & $2.1(0.8$ to 5.3$)$ & 0.12 & & \\
\hline \multicolumn{7}{|l|}{ Duration of ART (months) } \\
\hline $0-12$ & 413 & 77 (18.6) & & & & \\
\hline$>12$ & 516 & $116(22.5)$ & $1.3(0.9$ to 1.7$)$ & 0.15 & & \\
\hline \multicolumn{7}{|l|}{ Initial ART regimen } \\
\hline $\mathrm{AZT}+3 \mathrm{TC}+\mathrm{NVP} / \mathrm{EFV}$ & 411 & $97(23.6)$ & & & & \\
\hline D4T+3TC+NVP/EFV & 391 & $70(17.9)$ & 0.7 (0.5 to 1.0$)$ & 0.05 & & \\
\hline DDI-based regimen & 127 & $26(20.5)$ & $0.8(0.5$ to 1.4$)$ & 0.46 & & \\
\hline \multicolumn{7}{|l|}{ ART regimen at survey } \\
\hline AZT+3TC+NVP/EFV & 486 & $116(23.9)$ & & & & \\
\hline D4T+3TC+NVP/EFV & 323 & 49 (15.2) & $<0.01$ & & & \\
\hline DDI-based regimen & 90 & $20(22.2)$ & 0.74 & & & \\
\hline Second-line regimens & 30 & $8(26.7)$ & 0.73 & & & \\
\hline \multicolumn{7}{|c|}{ Missed doses in the past month } \\
\hline No & 794 & $153(19.3)$ & & & & \\
\hline Yes & 135 & 40 (29.6) & 1.8 (1.2 to 2.7$)$ & $<0.01$ & $1.6(1.0$ to 2.5$)$ & 0.03 \\
\hline \multicolumn{7}{|l|}{ CD4 cell counts at survey } \\
\hline$\geq 500$ & 140 & $16(11.4)$ & & & & \\
\hline 350-499 & 176 & $34(19.3)$ & 1.9 (1.0 to 3.5$)$ & 0.06 & 1.7 (0.9 to 3.3$)$ & 0.11 \\
\hline 200-349 & 285 & $66(23.2)$ & 2.3 (1.3 to 4.2$)$ & $<0.01$ & $2.2(1.2$ to 4.1$)$ & $<0.01$ \\
\hline $0-199$ & 328 & $77(23.5)$ & 2.4 (1.3 to 4.2$)$ & $<0.01$ & 2.9 (1.6 to 5.2$)$ & $<0.01$ \\
\hline \multicolumn{7}{|l|}{ Time of starting ART (year) } \\
\hline 2003-2007 & 528 & $103(19.5)$ & & & & \\
\hline 2008-2011 & 401 & $90(22.4)$ & $1.2(0.9$ to 1.6$)$ & 0.27 & & \\
\hline \multicolumn{7}{|l|}{ Province } \\
\hline Others & 623 & $158(25.4)$ & & & & \\
\hline Guangxi and Yunnan & 306 & 35 (11.4) & $0.4(0.3$ to 0.6$)$ & $<0.01$ & $0.4(0.2$ to 0.6$)$ & $<0.01$ \\
\hline
\end{tabular}


$\geq 500$ cells $/ \mathrm{mm}^{3}$ : CD4 350-499 AOR $1.7,95 \%$ CI 0.9 to 3.3, CD4 200-349 AOR 2.2, 95\% CI 1.2 to 4.1, CD4 0-199 AOR 2.9, 95\% CI 1.6 to 5.2). Compared to other provinces, residence in Guangxi and Yunnan provinces was negatively associated with virological failure (AOR $0.4,95 \%$ CI 0.2 to 0.6$)$.

\section{Sensitivity analysis}

Table 4 presents factors associated with HIV viral suppression failure at the time of starting ART from 2003 to 2007 and from 2008 to 2011, respectively. Only residence of Guangxi and Yunnan provinces was observed to be at lower risk than that in other provinces during 2003 and 2007 (OR=0.4, 95\% CI 0.2 to $0.6, \mathrm{p}<0.01)$ after adjusting for the initial ART regimen, ART regimen at survey, selfreported missing doses in the past month, and CD4 cell counts before ART. During 2008 and 2011, four factors were associated with virological failure, including province. Patients who were more likely to be virological failure were minorities $(\mathrm{OR}=2.3,95 \%$ CI 1.3 to 4.0, $\mathrm{p}<0.01)$, farmers $(\mathrm{OR}=2.1,95 \%$ CI 1.2 to $3.8, \mathrm{p}=0.01)$, CD4 200-349 or $0-199$ (OR=3.2, 95\% CI 1.3 to 7.9 , $\mathrm{p}=0.01$ and $\mathrm{OR}=4.1,95 \%$ CI 1.6 to $10.3, \mathrm{p}<0.01)$ and residence of Guangxi and Yunnan provinces was a protective factor $(\mathrm{OR}=0.3,95 \%$ CI 0.1 to $0.8, \mathrm{p}=0.01)$.

\section{DISCUSSION}

In this study, we analysed HIVDR data to evaluate the prevalence and risk factors of virological failure among IDUs at the national level. Our findings show that among 929 IDUs receiving free first-line ART, 20.8\% had virological failure (VL $\geq 1000$ copies $/ \mathrm{mL}$ ), which is higher than the outcomes of previous surveillance

Table 4 Multivariate analysis of factors associated with HIV viral suppression failure among IDU patients receiving antiretroviral treatment in China from 2003 to 2007 and 2008 to 2011

\begin{tabular}{|c|c|c|}
\hline \multirow[b]{2}{*}{ Variable } & \multicolumn{2}{|c|}{ Adjusted OR (95\% Cl) } \\
\hline & 2003-2007 & 2008-2011 \\
\hline \multicolumn{3}{|l|}{ Ethnicity } \\
\hline \multicolumn{3}{|l|}{ Han } \\
\hline Minorities & - & 2.3 (1.3 to 4.0$)$ \\
\hline \multicolumn{3}{|l|}{ Occupation } \\
\hline \multicolumn{3}{|l|}{ Others } \\
\hline Farmer & - & 2.1 (1.2 to 3.8$)$ \\
\hline \multicolumn{3}{|l|}{ CD4 cell counts } \\
\hline \multicolumn{3}{|l|}{ at survey } \\
\hline \multicolumn{3}{|l|}{$\geq 500$} \\
\hline \multicolumn{3}{|l|}{$350-499$} \\
\hline 200-349 & - & 3.2 (1.3 to 7.9$)$ \\
\hline 0-199 & - & 4.1 (1.6 to 10.3$)$ \\
\hline \multicolumn{3}{|l|}{ Province } \\
\hline \multicolumn{3}{|l|}{ Others } \\
\hline Guangxi and Yunnan & $0.4(0.2$ to 0.6$)$ & $0.3(0.1$ to 0.8$)$ \\
\hline
\end{tabular}

studies among other patient populations in China. ${ }^{9} 1314$ This suggests that treatment among IDUs has been less effective than in other high-risk populations, indicating a need for improved interventions.

Of the 193 patients who experienced failed viral suppression, 175 were successfully genotyped and 68 were identified as having drug resistance mutations. The prevalence of HIVDR among patients with virological failure was $38.9 \%(68 / 175)$, which suggested that HIVDR was one of the most important factors associated with virological failure, and further researches should be focused on other potential factors. 36 (52.9\%) had NNRTI mutations, $52(76.5 \%)$ had NRTI mutations and $3(4.4 \%)$ had PI mutations. In addition, 21 (30.9\%) were resistant to dual-class drugs. Similar to other studies in China, K103N/R and M184I/V were the most common NNRTI and NRTI mutations, respectively. ${ }^{9} 13$ Since three patients had detectable drug resistance to PIs, drugs such as second-line regimens should be used judiciously.

Our study found that minorities, people with junior high school or lower education levels and farmers were the three sociodemographic factors associated with virological failure. IDUs are more commonly found in southwest China, where there is an abundant multiethnic presence. Owing to sparser population distributions and lower income levels province-wide, these people generally received lower levels of education. ${ }^{15} \mathrm{In}$ addition, traditional cultures and religions may pose obstacles to efficient implementation of CDC-based interventions. ${ }^{16}$ Similarly, most HIV-infected farmers live in rural areas, where income levels were low and healthcare infrastructure is poor, which compromises ART administration; this is corroborated by another research study conducted at three sentinel surveillance sites in China. ${ }^{14}$ Thus, efforts should be carried out in order to raise awareness, strengthen health education and train doctors at villages and townships regularly; supplemental policies should aim to improve income and healthcare infrastructure in rural areas.

Poor ART adherence was another risk factor in our study, with 135 (14.5\%) patients having reported missing doses in the past month, which was higher than that of other studies in China. ${ }^{9} 1013$ Except for one study from Indonesia which showed that adherence to ART was no different between IDUs and non-IDUs, ${ }^{17}$ some international studies have found that IDUs tend to have lower ART adherence rates than non-IDUs. ${ }^{18}{ }^{19}$ Non-adherence is associated with depression, a lack of stable relationships and active drug injection. ${ }^{20-22}$ Good adherence can promise suppression of plasma HIV RNA and utilise the optimum effectiveness of the ART therapy. ${ }^{23}$ Several international studies have focused on strategies to improve adherence, including behavioural interventions, social support, ${ }^{24}$ directly administered antiretroviral therapy (DAART) ${ }^{25}$ and MMT. ${ }^{26-28}$ These studies have found that drug adherence education should be part of the rehabilitation treatment 
programme for IDUs as well as a further expansion of health services.

Finally, when compared to other provinces, a lower proportion of IDUs in Guangxi and Yunnan experienced virological failure. IDUs are the main high-risk population for HIV infection in Guangxi, Yunnan and Xinjiang; however, in our study of 306 patients from Xinjiang, 87 (28.4\%) had virological failure, of which 85 were successfully genotyped and 28 were found to have drug resistance. This finding indicated that Xinjiang had worse effectiveness of treatment, which was corroborated by a previous study showing that patients from Xinjiang were 12.6 times more likely to develop virological failure when compared to those from Guangxi and Yunnan. ${ }^{13}$ Of the 306 patients from Guangxi and Yunnan, 28 $(9.2 \%)$ had missed doses in the past month, compared to $107(17.2 \%)$ in other provinces. This supports the hypothesis that achieving good adherence is one of the most effective means to viral suppression. Similarly, a study in Guangxi reported that of the 120 patients receiving antiretroviral treatment, $113(94.2 \%)$ took their medicine on time. The Guangxi CDC has a series of standard measurement protocols to supervise patient adherence: strict regulation of HIV drugs, regular followups, treatment of opportunistic infections and strongly prioritised use of first-line regimens. ${ }^{29}$ Large-scale ART treatment was implemented in Yunnan province in 2004; patients receiving free antiretroviral treatment in Yunnan had better survival effects. ${ }^{30}$ In our study, the prevalence of virological failure among IDUs in Yunnan was low, which was supported by the results of local research. ${ }^{31}$

After MMT was implemented nationwide in 2004, the prevalence of HIV infection among IDUs was better controlled. ${ }^{6}$ Many studies have shown that MMT is a costeffective intervention to scale up acceptance and adherence to HAART and improve the effectiveness of therapy among IDUs. ${ }^{16}{ }^{26}{ }^{27}$ However, adherence to MMT is itself associated with age, stable employment, alcohol abuse and coverage of ART. ${ }^{32}{ }^{33}$ Hence, more strategies are needed to examine improving MMT retention.

Through the sensitivity analysis, some details would be presented. Before 2008, province was the only factor associated with virological failure; however, in addition to province, three more factors were found to be significantly associated with virological failure after 2008: ethnicity, occupation and CD4 cell counts at survey. Enlarging the sample size is an effective way to reduce biases and after combining the several cross-sectional surveys, education and self-reported missing doses in the past month were included into the final multivariate logistic regression models.

This study has several limitations. First, the data in our study was from the Chinese National HIVDR Surveillance and Monitoring Network, which may or may not fully represent all IDUs in China. Second, the study sample included patients starting antiretroviral treatment from 2003 to 2011, during which period prevention policies and treatment programmes have undergone many significant changes that have most likely influenced treatment efficacy. Lastly, our study provided a systematic examination of the treatment outcomes of IDUs in China. However, as the epidemic and intervention situations differ across diverse localities, intervention and prevention measures should be tailored differently as well.

It has been more than 10 years since the China's National Free Antiretroviral Treatment Program (NFATP) was put into effect in 2003. During this time span, this programme has matured and improved and, as a result, more and more HIV-infected patients have gained access to antiretroviral therapy; this has brought the HIV/AIDS epidemic under control. The implementation of NFATP has had some successful examples, such as Guangxi and Yunnan, with success in dealing with antiretroviral treatment among IDUs; however, poor adherence to treatment is still a key problem, which has led to the high rate of failure of viral suppression among IDUs. More research is needed in order to explore how to improve the adherence of IDUs.

\section{Author affiliations}

${ }^{1}$ State Key Laboratory for Infectious Disease Prevention and Control, National Center for AIDS/STD Control and Prevention, Chinese Center for Disease Control and Prevention, Collaborative Innovation Center for Diagnosis and Treatment of Infectious Diseases, Beijing, China

${ }^{2}$ Guangxi Center for Disease Control and Prevention, Nanning, Guangxi, China ${ }^{3}$ Yunnan Center for Disease Control and Prevention, Kunming, Yunnan, China

${ }^{4}$ Xinjiang Autonomous Region Center for Disease Control and Prevention,

Urumqi, Xinjiang, China

${ }^{5}$ University of North Texas Health Science Center Graduate School of Biomedical Sciences, Fort Worth, Texas, USA

Contributors HX, YR and YS were responsible for the conception and design of this study. SL, YM, YD, LL, JW and CH performed the study. XL, WK and $\mathrm{HZ}$ were involved in the data cleaning and statistical analysis. XL, DG and JHH accomplished the drafted manuscript. All authors reviewed and approved the final manuscript.

Funding This study was supported by grants from the Ministry of Science and Technology of China (2012ZX10001-002), Guangxi Honor Scholar, Chinese State Key Laboratory for Infectious Disease Develop Grant, and the International Development Research Center of Canada (grant \#104519-010).

Competing interests None.

Ethics approval The institutional review board (IRB) of the NCAIDS, China CDC approved this study.

Provenance and peer review Not commissioned; externally peer reviewed.

Data sharing statement No additional data are available.

Open Access This is an Open Access article distributed in accordance with the Creative Commons Attribution Non Commercial (CC BY-NC 4.0) license, which permits others to distribute, remix, adapt, build upon this work noncommercially, and license their derivative works on different terms, provided the original work is properly cited and the use is non-commercial. See: http:// creativecommons.org/licenses/by-nc/4.0/

\section{REFERENCES}

1. Connor EM, Sperling RS, Gelber R, et al. Reduction of maternal-infant transmission of human immunodeficiency virus type 1 with zidovudine treatment. N Engl J Med 1994;331:1173-80. 
2. Patel D, Desai M, Shah AN, et al. Early outcome of second line antiretroviral therapy in treatment-experienced human immunodeficiency virus positive patients. Perspect Clin Res 2013;4:215-20.

3. Zhang F, Dou Z, Ma Y, et al. Five year outcomes of the China national free antiretroviral treatment program. Ann Intern Med 2009;151:241-51.

4. Sanguansittianant S, Nooroon N, Phaengchomduan P, et al. Trends in prevalence of HIV-1 drug resistance in Thailand 2009-2010. J Clin Lab Anal 2013;27:346-53.

5. UNAIDS Global report: UNAIDS report on the global AIDS epidemic 2012. UNAIDS

6. 2011 Report on the estimation of HIV epidemic in China. Beijing: Ministry of Health, PRC, UNAIDS, World Health Organization, 2011.

7. Zhang L, Chow EP, Jing J, et al. HIV prevalence in China: integration of surveillance data and a systematic review. Lancet Infect Dis 2013;13:955-63.

8. Chinese Center for Disease Control and Prevention: Analysis of HIV/ STD epidemic in 2013. Beijing, China.

9. Wang $\mathrm{J}, \mathrm{He} \mathrm{C}, \mathrm{Hsi} \mathrm{JH}$, et al. Virological outcomes and drug resistance in Chinese patients after 12 months of 3TC-based first-line antiretroviral treatment, 2011-2012. PLOS ONE 2014;9: e88305.

10. Xing H, Ruan $\mathrm{Y}$, Li J, et al. HIV drug resistance and its impact on antiretroviral therapy in Chinese HIV-infected patients. PLOS ONE 2013;8:e54917.

11. Zhong $P, P a n Q, N i n g ~ Z$, et al. Genetic diversity and drug resistance of human immunodeficiency virus type 1 (HIV-1) strains circulating in Shanghai. AIDS Res Hum Retroviruses 2007;23:847-56.

12. Liu TF, Shafer RW. Web resources for HIV type 1 genotypic-resistance test interpretation. Clin Infect Dis 2006;42:1608-18.

13. Wang $\mathrm{X}$, Yang L, Li H, et al. Factors associated with HIV virologic failure among patients on HAART for one year at three sentinel surveillance sites in China. Curr HIV Res 2011;9:103-11.

14. Ruan $\mathrm{Y}$, Xing $\mathrm{H}$, Wang $\mathrm{X}$, et al. Virologic outcomes of first-line HAART and associated factors among Chinese patients with HIV in three sentinel antiretroviral treatment sites. Trop Med Int Health 2010;15:1357-63.

15. Wang QX, Wang X, Chen B, et al. Drug resistance and associated factors on HIV in Liangshan prefecture, Sichuan province. Zhonghua Liu Xing Bing Xue Za Zhi 2011;32:1082-6.

16. Li H, Zhong M, Guo M, et al. Prevalence and mutation patterns of HIV drug resistance from 2010 to 2011 among ART-failure individuals in the Yunnan province, China. PLOS ONE 2013;8: e72630.

17. Wisaksana R, Indrati AK, Fibriani A, et al. Response to first-line antiretroviral treatment among human immunodeficiency virus-infected patients with and without a history of injecting drug use in Indonesia. Addiction 2010;105:1055-61.

18. Zaccarelli $\mathrm{M}$, Barracchini $\mathrm{A}$, De Longis $\mathrm{P}$, et al. Factors related to virologic failure among HIV-positive injecting drug users treated with combination antiretroviral therapy including two nucleoside reverse transcriptase inhibitors and Nevirapine. AIDS Patient Care STDS 2002; 16:67-73.
19. Knobel H, Guelar A, Carmona A, et al. Virologic outcome and predictors of virologic failure of highly active antiretroviral therapy containing protease inhibitors. AIDS Patient Care STDS 2001:15:193-9.

20. Waldrop-Valverde D, Valverde E. Homelessness and psychological distress as contributors to antiretroviral nonadherence in HIV-positive injecting drug users. AIDS Patient Care STDS 2005;19:326-34.

21. Tucker JS, Burnarn MA, Sherbourne CD, et al. Substance use and mental health correlates of nonadherence to antiretroviral medications in a sample of patients with human immunodeficiency virus infection. Am J Med 2003;114:573-80.

22. Carrieri MP, Chesney MA, Spire B, et al. Failure to maintain adherence to HAART in a cohort of French HIV-positive injecting drug users. Int J Behav Med 2003;10:1-14.

23. Nolan S, Milloy MJ, Zhang R, et al. Adherence and plasma HIV RNA response to antiretroviral therapy among HIV-seropositive injection drug users in a Canadian setting. AIDS Care 2011;23:980-7.

24. Simoni JM, Amico KR, Pearson CR, et al. Strategies for promoting adherence to antiretroviral therapy: a review of the literature. Curr Infect Dis Rep 2008;10:515-21.

25. Altice FL, Mezger JA, Hodges J, et al. Developing a directly administered antiretroviral therapy intervention for HIV-infected drug users: implications for program replication. Clin Infect Dis 2004;38 (Suppl 5):S376-387.

26. Clarke S, Delamere S, McCullough L, et al. Assessing limiting factors to the acceptance of antiretroviral therapy in a large cohort of injecting drug users. HIV Med 2003;4:33-7.

27. Uhlmann S, Milloy MJ, Kerr T, et al. Methadone maintenance therapy promotes initiation of antiretroviral therapy among injection drug users. Addiction 2010;105:907-13.

28. Roux P, Carrieri MP, Villes V, et al. The impact of methadone or buprenorphine treatment and ongoing injection on highly active antiretroviral therapy (HAART) adherence evidence from the MANIF2000 cohort study. Addiction 2008;103:1828-36.

29. Li HP, Liu W, Liu HX, et al. Study on the antiviral therapy program among people with human immunodeficiency virus in Guangxi Zhuang Authority. Zhonghua Liu Xing Bing Xue Za Zhi 2007;28:338-42.

30. Yao ST, Duan S, Xiang LF, et al. Survival analysis on $3103 \mathrm{HIV} /$ AIDS patients receiving antiretroviral treatment in Dehong prefecture, Yunnan province. Zhonghua Liu Xing Bing Xue Za Zhi 2010;31:1215-18.

31. Yao S, Yang J, Zhou L, et al. Study on HIV viral load in plasma and drug resistance among AIDS patients receiving antiretroviral treatment in Dehong prefecture,Yunnan province. Zhonghua Liu Xing Bing Xue Za Zhi 2014;35:411-16.

32. Jiang $\mathrm{H}, \mathrm{Cao} \mathrm{X}$, Wang $\mathrm{C}$, et al. Study on the adherence and related determinants among HIV-positive clients under methadone maintenance treatment in Dali, Yunnan province from 2005 to 2013. Zhonghua Liu Xing Bing Xue Za Zhi 2014;35:255-8.

33. Jiang $\mathrm{H}, \mathrm{Han} Y, \mathrm{Du} J$, et al. Factors associated with one year retention to methadone maintenance treatment program among patients with heroin dependence in China. Subst Abuse Treat Prev Policy 2014;9:11. 